\title{
Chronic knee extensor mechanism lesions in total knee arthroplasty: a literature review
}

\author{
UMBERTO COTTINO, DAVIDE DELEDDA, FEDERICA ROSSO, DAVIDE BLONNA, \\ DAVIDE EDOARDO BONASIA, ROBERTO ROSSI
}

\author{
Department of Orthopedic Surgery Mauriziano "Umberto I" Hospital, Torino, Italy
}

\begin{abstract}
Knee extensor mechanism rupture is a serious complication of total knee arthroplasty (TKA). Its prevalence ranges from 1 to $10 \%$ and it is commonly observed as a chronic multifactorial pathology with the patellar tendon as the most common site of rupture.

Knee extensor mechanism reconstruction can be performed using allogenic or synthetic grafts. In the literature it is still not clear whether one of these techniques is superior to the other and the choice is usually tailored to the patient case by case. Allografts allow better restoration of the anatomical landmarks, whereas the mesh technique is more reproducible and the graft does not elongate over time. Allografts carry an increased risk of infection compared with synthetic reconstructions, while the mesh technique is cheaper and more readily available.

In this paper, we review the etiology, diagnosis and treatment of this pathology, drawing on the most recent literature.
\end{abstract}

Keywords: allograft reconstruction, chronic rupture, extensor mechanism, knee revision, prosthesis failure, synthetic graft.

\section{Introduction}

Extensor mechanism rupture is one of the most feared complications of total knee arthroplasty (TKA). Its

\footnotetext{
Corresponding Author:

Umberto Cottino, MD

Department of Orthopedic Surgery Mauriziano "Umberto I" Hospital

Via Ferdinando Magellano 1, 10128 Torino, Italy

E-mail: umberto.cottino@gmail.com
}

reported prevalence ranges from 1 to $10 \%$ and it is most commonly described as a chronic lesion (1-3). This complication is related to different factors, such as intra-operative procedures and patient characteristics (4). Extensor mechanism repair is a very challenging procedure with major implications for the good functioning of the TKA. Several techniques for extensor mechanism repair have been reported in the literature and different grafts have been utilized. In chronic lesions, knee extensor mechanism reconstruction can usually be performed using allogenic or synthetic grafts. Allografts can be fresh-frozen or freeze-dried; the Achilles tendon or the complete extensor mechanism are suitable grafts. The synthetic graft most commonly used is the Marlex mesh used in abdominal repair (5). In this paper we report the most common causes of extensor mechanism rupture after TKA and describe the most common repair procedures; we also describe the treatment that, on the basis of our own experience, we choose to perform.

\section{Etiology}

The extensor mechanism of the knee is composed of the quadriceps tendon, the patella and the patellar tendon. The patellar tendon is the most common site of rupture, and this is most likely to occur at the tibial insertion. Patellar tendon ruptures have been reported to account for between 0.17 and $0.55 \%$ of all TKAs (1). The injury mechanism can be a fall with a direct trauma or impingement on the prosthetic components (3). Quadriceps tendon rupture reportedly occurs after $0.1 \%$ of all TKAs, and it is definitely the least common cause of knee extensor mechanism failure (6). Patellar fracture can occur in the presence of either an un-resurfaced or a resurfaced patella. It is rarely associated with 
a traumatic event; indeed, in $88 \%$ of cases the etiology is atraumatic (fatigue strain). Predisposing factors for patellar fracture are (7-14): excessive lateral release, excessive bone removal, peg fixation and cementation, improper patellar tracking (malalignment), rheumatoid arthritis, patellar necrosis, surgical technique, and prolonged steroid use.

If the fracture is stable a non-surgical approach can be attempted; in displaced fractures, on the other hand, a surgical treatment is required. In cases in which surgical reconstruction is required, open reduction and internal fixation with tension band or cerclage wiring is the first choice of treatment, even though the posttreatment rate of failure and subsequent non-union may be as high as $90 \%$ (15).

The minimum force needed to break a healthy patellar tendon has been measured in biomechanical studies and found to be close to 17.5 times the individual's body weight (16). This is an impressive amount of force in relation to activities of normal daily living: climbing stairs generates only 3.2 times a person's body weight (17). Strain forces are found to be higher at the osteotendinuous insertion than in the middle of the tendon, and thus more commonly produce avulsions than mid-substance lesions. Given the great strength of this tendon, ruptures tend to occur in degenerated tendons; this can be noted especially in the case of mid-substance lesions (18). Various Authors have described other health conditions predisposing to patellar tendon rupture, such as: local injections of corticosteroids (19), diabetes (19-21), microtrauma (20), rheumatic diseases (3), metabolic disorders (3), iatrogenic lesions (anterior cruciate ligament reconstruction with patellar tendon graft) (22), and systemic use of fluoroquinolones $(23,24)$.

In addition to these causes, when lesions occur in patients with TKAs we have to consider the soft tissue damage due to the previous surgical approach and procedure, which may have compromised the blood supply from the medial branch of the genicular artery and impaired the patellar bone quality. The medial genicular artery is the most damaged when using medial parapatellar arthrotomy, the most common approach in knee reconstruction surgery. In addition to this, microtraumatic damage of the patellar tendon has been described, attributable to impingement on the polyethylene insert (2).

\section{Clinical examination and imaging}

A good anamnesis is the first step in approaching an extensor mechanism rupture. Patients usually report pain followed by knee impotence, but no trauma. In the history-taking stage, the surgeon must investigate whether there have been previous episodes of pain, and establish whether the patient presents comorbidities that can affect the tendons and patella (diabetes, rheumatoid arthritis, corticosteroid injections, etc.). Clinically, on inspection, the knee is normally swollen, and sometimes the patella cannot be palpated because of edema resulting from the lesion. When the patellar tendon or the patella are involved in the lesion, the patient may show patella alta. In chronic lesions, intrarticular hematoma is often absent, but if it is present, we recommend evacuating the intra-articular fluid in a surgical theater because of the risk of infection. Liquid aspiration can be useful for differential diagnosis in uncertain cases. In cases of partial extensor mechanism rupture, extension may be possible, even with pain. In the presence of a complete tear, a lag sign can be observed and extension movements against gravity cannot be accomplished.

The first instrumental investigation should be a plain radiograph in three projections (anteroposterior, laterolateral and sunset view) in order to evaluate the bony landmarks of the knee and to exclude fractures around the prosthesis. The Insall-Salvati ratio must be calculated: this can be useful for comparing the position of the patella with its position on previous radiographs, and it can be suggestive of patellar tendon lesions. In these cases, it can prove useful to perform an ultrasound scan as this may show a hypo-echoic area within the proximal patellar tendon, and also because this examination can be executed dynamically. Its limitations, however, are its low reproducibility and subjectivity. We normally use computed tomography for diagnosing extensor mechanism rupture because the image quality it gives in the presence of a prosthesis is higher than that obtained with magnetic resonance imaging, and this allows us to better evaluate the quality of the bone around the TKA.

\section{Allograft repair}

The Achilles tendon with bone block or the whole knee extensor mechanism are the allografts normally 
used for extensor mechanism repair. The choice of allograft depends on the residual tissue available, particularly the patellar bone stock. If the bone stock is inadequate or the patella is found to be difficult to mobilize a whole extensor mechanism allograft is indicated. Patients with an intact and mobile patella (the inferior pole can be brought down to within $2-3 \mathrm{~cm}$ of the joint line) are candidates for an Achilles tendon graft. Homologous tissue grafts allow better anatomical reconstruction of the extensor mechanism and the graft is usually completely incorporated into the host tissue (25). Allografts can be fresh-frozen or freezedried: the best results may be achieved with freshfrozen allografts because of the greater strength of the graft (26). Emerson et al. were the first to describe an allograft reconstruction technique performed using a whole extensor mechanism (fresh-frozen or freezedried) (19, 27). Nazarian and Booth (21) then improved this technique in order to avoid the extensor lag of 20 to $40^{\circ}$ lasted in almost $30 \%$ of the treated knees. They showed that the allograft should be tensioned in full extension.

In 2008 Malhotra et al. (20) described a new extensor mechanism reconstruction technique in which a composite allograft consisting of a patella-patellar tendontibial tubercle was used to repair the extensor mechanism in the presence of a good patellar bone stock. One problem encountered was delayed proximal graft healing at the bone-tendon interface.

\section{Complete extensor mechanism allograft}

This graft is composed of the proximal tibia, the patellar tendon, the patella and 5 to $8 \mathrm{~cm}$ of quadriceps tendon (28). In the literature, fresh-frozen grafts were reported to give better results compared with freeze-dried ones (19). We recommend checking the integrity and the appropriateness of the graft before surgery.

The skin incision should be performed on the previous scar, but if it is impossible to approach the whole extensor mechanism (i.e. sub-vastus, mid-vastus, mini incision, etc.), a new incision can be made following a new line, always respecting the basic principles for skin health and blood supply. The dissection is taken down along the midline to expose the extensor mechanism. The retinaculum dissection is performed through the extensor mechanism, creating medial and lateral flaps.
In every case, even if the diagnosis is a chronic rupture of the tendon and there are no clinical signs of infection, it is recommended to perform a bacteriological test.

The patella is then longitudinally osteotomized following the midline and carefully removed. If required, the bone should be used as autologous bone graft material. The midline incision is carried into the host quadriceps proximally and distally over the host tibial tubercle.

During this surgical step the allograft is prepared on a back table. Before creating any tibial trough the allograft tibial bone is marked and prepared as planned before surgery, to ensure a perfect press-fit. The length of the bone block should be from 5 to $8 \mathrm{~cm}$ above the articular surface of the allograft to the distal cut. The width and the depth of the block is approximately $1.5-2 \mathrm{~cm}$. It is better to perform a conservative cut and then cut more if necessary. We mark an angle of $25^{\circ}$ to $45^{\circ}$ on the tibial proximal bone block and cut it carefully about $25 \mathrm{~mm}$ long to guarantee a good press-fit of the allograft (the same procedure is performed on the allograft tibial bone).

The allograft should subsequently be secured with two to three stainless steel wires. The bone shape created on the tibial allograft block ensures that it will engage the host bone during the tensioning. At this point, the quadriceps tendon is fixed with non-absorbable suture that will be used afterwards to tension the allograft. Once the allograft is tensioned, the steel wires are tightened and cut, then bent in a lateral position to avoid damage to the soft tissues. After surgery the knee is placed in full extension using a brace that allows wound control.

The full extension is maintained for eight weeks, avoiding full weight bearing. After this period, $30^{\circ}$ of active flexion is achieved, placing the knee in a hinged knee brace, and patients can start weight bearing gradually. At 12 weeks, the maximum flexion is increased to $90^{\circ}$; gradually full flexion is gradually achieved before six months.

\section{Achilles tendon allograft}

As with the previous procedure, in Achilles tendon allograft reconstruction, the skin incision should be performed on the previous scar and can follow a new line only if this respects the basic principles for skin health and blood supply (29). A medial parapatellar 
arthrotomy is performed and the patellar tendon is dissected from the surrounding soft tissues. The proximal extensor mechanism is dissected and mobilized proximally to obtain a better placement of the patella. The tibial metaphysis is prepared with a trough measuring approximately $2 \mathrm{~cm}$ in length and $1 \mathrm{~cm}$ in width and depth to receive the calcaneal bone block of the allograft. The position is chosen by placing the extensor mechanism in normal alignment. The calcaneal bone block is then cut to fit in the trough created in the tibia and then fixed in place with a cortical screw. A metal wire may be used to strengthen the boneblock fixation.

The Achilles tendon allograft is overturned on the joint capsule and sutured to the underlying extensor mechanism. The knee is positioned in complete extension and the allograft tensioned in a proximal direction and sutured to the quadriceps tendon (Tab. 1).

\section{Marlex-Mesh reconstruction}

This technique was first described by Browne and Hanssen in 2011 for the treatment of subacute or chronic knee extensor mechanism rupture (5). The reconstruction is performed with a synthetic graft folded in a sheet measuring $10 \times 14$ inches $(25.4 \times 35.6 \mathrm{~cm})$ and sutured with heavy non-absorbable suture. A slot is prepared in the anterior aspect of the tibia in a position corresponding to the anterior tibial tuberosity, where the free end of the mesh graft is inserted into the medullary canal. It must be secured with cement and transfixed with a screw distal to the trough. In the case of a stable tibial component the free end of the graft should be fixed on the anteromedial aspect of the tibia using big non-absorbable sutures and tibial tunnels. The graft is then passed into the lateral aspect of the knee through the soft tissues and from deep to superficial.

Table 1. Literature results for reconstruction of the knee extensor mechanism.

\begin{tabular}{|c|c|c|}
\hline Author & Analysis & Results \\
\hline Crosset et al. (29) & $\begin{array}{l}\text { Reconstruction of patellar tendon with an } \\
\text { Achilles tendon allograft in total knee } \\
\text { arthroplasty }\end{array}$ & $\begin{array}{l}\text { In TKA the Achilles tendon was found to provide } \\
\text { reliable reconstruction of a ruptured patellar tendon. } \\
\text { Surgery indicated for patients with multiple prior } \\
\text { operations }\end{array}$ \\
\hline Barrack et al. (28) & $\begin{array}{l}14 \text { patients with chronic extensor } \\
\text { mechanism disruption treated with } \\
\text { allograft reconstruction }\end{array}$ & $\begin{array}{l}\text { Improvement of patients' functional status and } \\
\text { satisfaction }\end{array}$ \\
\hline Malhotra et al. (20) & $\begin{array}{l}\text { Reconstruction (following patellar tendon } \\
\text { loss) with an extensor mechanism } \\
\text { composite allograft }\end{array}$ & $\begin{array}{l}\text { Encouraging results in the management of a failed } \\
\text { extensor mechanism after TKA }\end{array}$ \\
\hline Springer and Della Valle (26) & $\begin{array}{l}\text { Options for allograft reconstruction with } \\
\text { an Achilles tendon bone block allograft or } \\
\text { a whole extensor mechanism allograf }\end{array}$ & $\begin{array}{l}\text { Current results with proper surgical technique show } \\
\text { acceptable functional outcome after disruption of the } \\
\text { extensor mechanism, a devastating TKA complication }\end{array}$ \\
\hline Browne and Hanssen (5) & $\begin{array}{l}\text { Surgical technique using synthetic mesh } \\
\text { for patellar tendon reconstruction }\end{array}$ & $\begin{array}{l}\text { Successful and durable technique in the majority of } \\
\text { patients. No complications related to synthetic mesh } \\
\text { use }\end{array}$ \\
\hline Nam et al. (30) & $\begin{array}{l}\text { Analysis of: patellar tendon disruption, } \\
\text { quadriceps tendon rupture, patellar crepitus } \\
\text { and soft-tissue impingement, periprosthetic } \\
\text { patellar fracture, patellofemoral instability, } \\
\text { and osteonecrosis of the patella }\end{array}$ & $\begin{array}{l}\text { Treatment of these complications is often poor, and } \\
\text { management of patient expectations is important }\end{array}$ \\
\hline
\end{tabular}


The patella and quadriceps tendon are mobilized, correctly positioned and then sutured to the graft in order to secure it to the lateral retinaculum, the vastus lateralis muscle and the quadriceps tendon. The vastus medialis muscle (VMO) then has to be mobilized and passed over the graft in a pants-over-vest manner, after which it has to be sutured, including the entire graft in the soft tissues and avoiding direct contact with the subcutaneous tissue (Fig. 1). This procedure is inexpensive and easy to perform and reportedly achieves good lag recovery without lengthening of the graft. Moreover, it allows the revision to be performed earlier as it is not dependent on allograft availability, and the risk of disease transmission is reduced (30).

\section{Conclusions}

In conclusion, extensor mechanism rupture is a highly complex and challenging complication of total knee arthroplasty. The first steps are to obtain a complete history and perform a correct clinical investigation; the history as told by the patient can be extremely helpful for diagnosis, but it must be analyzed and confirmed by instrumental evaluation in order to locate and measure the lesion. In chronic lesions, repair is not suitable due to tissue loss and reconstruction is the only option. Reconstruction can be performed using an allograft or synthetic graft (mesh). The literature does not indicate whether either of these techniques is superior to the other and the choice must be made on the basis of the surgeon's preference.

Allografts allow better restoration of the anatomical landmarks but are associated with a longer period of integration and a physiological lengthening of the graft. Moreover, allografts are quite difficult to find and the technique is much more complex compared with use of a mesh. The mesh technique is more reproducible, easier to perform, and not subject to graft lengthening. Furthermore, allografts can be a vehicle for infections, whereas with meshes this risk is reduced. Finally, with the mesh technique the delay while waiting for a graft is reduced to zero. For these reasons, and also in view of the good results we have obtained in our own clinical practice, we prefer the mesh technique.

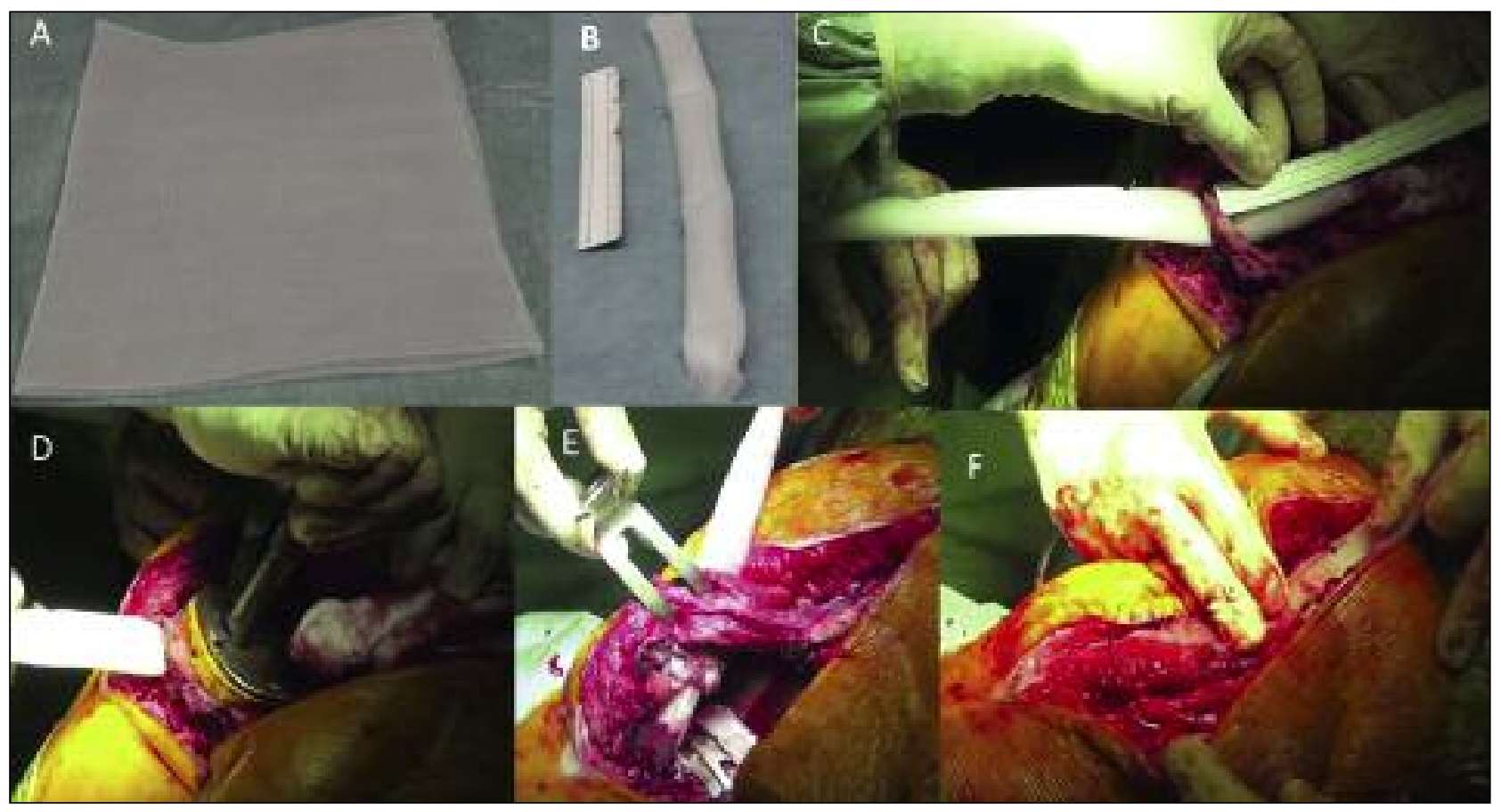

Fig. 1. Main steps in the Marlex mesh technique. A: 10 x 14-inch Marlex mesh sheet. B: Mesh sutured with heavy non-absorbable suture. C: Slot in the anterior aspect of the tibia. D: Mesh cemented into the intramedullary canal. E: Graft passed into the lateral aspect of the knee. F: Proximal suture of the extensor mechanism in a pants-over-vest manner on the graft. 


\section{oints}

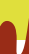

\section{References}

1. Rand JA, Morrey BF, Bryan RS. Patellar tendon rupture after total knee arthroplasty. Clin Orthop Relat Res. 1989;(244): 233-238

2. Parker DA, Dunbar MJ, Rorabeck CH. Extensor mechanism failure associated with total knee arthroplasty: prevention and management. J Am Acad Orthop Surg. 2003;11:238-247.

3. Lynch AF, Rorabeck CH, Bourne RB. Extensor mechanism complications following total knee arthroplasty. J Arthroplasty. 1987;2:135-140.

4. Fehring TK, Odum S, Griffin WL, et al. Early failures in total knee arthroplasty. Clin Orthop Relat Res. 2001;(392):315-318.

5. Browne JA, Hanssen AD. Reconstruction of patellar tendon disruption after total knee arthroplasty: results of a new technique utilizing synthetic mesh. J Bone Joint Surg Am. 2011; 93:1137-1143.

6. Dobbs RE, Hanssen AD, Lewallen DG, et al. Quadriceps tendon rupture after total knee arthroplasty. Prevalence, complications, and outcomes. J Bone Joint Surg Am. 2005;87:37-45.

7. Yoo JD, Kim NK. Periprosthetic fractures following total knee arthroplasty. Knee Surg Relat Res. 2015;27:1-9.

8. Backstein D, Safir O, Gross A. Periprosthetic fractures of the knee. J Arthroplasty. 2007;22(4 Suppl 1):45-49.

9. Goldberg VM, Figgie HE 3rd, Inglis AE, et al. Patellar fracture type and prognosis in condylar total knee arthroplasty. Clin Orthop Relat Res. 1988(236):115-122.

10. Windsor RE, Scuderi GR, Insall JN. Patellar fractures in total knee arthroplasty. J Arthroplasty. 1989;4 Suppl:S63-67.

11. Ortiguera CJ, Berry DJ. Patellar fracture after total knee arthroplasty. J Bone Joint Surg Am. 2002;84-A:532-540.

12. Huberti HH, Hayes WC. Patellofemoral contact pressures. The influence of q-angle and tendofemoral contact. J Bone Joint Surg Am. 1984;66:715-724.

13. Wetzner SM, Bezreh JS, Scott RD, et al. Bone scanning in the assessment of patellar viability following knee replacement. Clin Orthop Relat Res. 1985(199):215-219.

14. Goldstein SA, Coale E, Weiss AP, et al. Patellar surface strain. J Orthop Res. 1986;4:372-377.

15. Chalidis BE, Tsiridis E, Tragas AA, et al. Management of periprosthetic patellar fractures. A systematic review of literature. Injury 2007;38:714-724.

16. Zernicke RF, Garhammer J, Jobe FW. Human patellar-tendon rupture. J Bone Joint Surg Am. 1977;59:179-183.

17. Matava MJ. Patellar tendon ruptures. J Am Acad Orthop Surg. 1996;4:287-296.
18. Kelly DW, Carter VS, Jobe FW, et al. Patellar and quadriceps tendon ruptures-jumper's knee. Am J Sports Med. 1984;12:375-380.

19. Emerson RH Jr, Head WC, Malinin TI. Extensor mechanism reconstruction with an allograft after total knee arthroplasty. Clin Orthop Relat Res. 1994;303:79-85.

20. Malhotra R, Garg B, Logani V, et al. Management of extensor mechanism deficit as a consequence of patellar tendon loss in total knee arthroplasty: a new surgical technique. J Arthroplasty. 2008;23:1146-1151.

21. Nazarian DG, Booth RE Jr. Extensor mechanism allografts in total knee arthroplasty. Clin Orthop Relat Res. 1999; (367):123-129.

22. Benner RW, Shelbourne KD, Urch SE, et al. Tear patterns, surgical repair, and clinical outcomes of patellar tendon ruptures after anterior cruciate ligament reconstruction with a bone-patellar tendon-bone autograft. Am J Sports Med. 2012;40:1834-1841.

23. Stinner DJ, Orr JD, Hsu JR. Fluoroquinolone-associated bilateral patellar tendon rupture: a case report and review of the literature. Mil Med. 2010;175:457-459.

24. Stephenson AL, Wu W, Cortes D, et al. Tendon injury and fluoroquinolone use: a systematic review. Drug Saf. 2013;36: 709-721.

25. Burnett RS, Fornasier VL, Haydon CM, et al. Retrieval of a well-functioning extensor mechanism allograft from a total knee arthroplasty. Clinical and histological findings. J Bone Joint Surg Br. 2004;86:986-990.

26. Springer BD, Della Valle CJ. Extensor mechanism allograft reconstruction after total knee arthroplasty. J Arthroplasty. 2008;23(7 Suppl):35-38.

27. Emerson RH Jr, Head WC, Malinin TI. Reconstruction of patellar tendon rupture after total knee arthroplasty with an extensor mechanism allograft. Clin Orthop Relat Res. 1990;(260):154-161.

28. Barrack RL, Stanley T, Allen Butler R. Treating extensor mechanism disruption after total knee arthroplasty. Clin Orthop Relat Res. 2003; (416):98-104.

29. Crossett LS, Sinha RK, Sechriest VF, et al. Reconstruction of a ruptured patellar tendon with achilles tendon allograft following total knee arthroplasty. J Bone Joint Surg Am. 2002; 84-A:1354-1361.

30. Nam D, Abdel MP, Cross MB, et al. The management of extensor mechanism complications in total knee arthroplasty. AAOS exhibit selection. J Bone Joint Surg Am. 2014;96:e47. 